\title{
シヤイロ・ンンクロトロン放邲に 対する磁化プラズマの影梆*
}

\author{
京大工 小川忠济大* \\ 桜井帮朋 $* *$
}

( 1968 年 4 月 4 日受理)

\section{$\underline{\text { ABSTRACT }}$}

The gyro-synchrotron radiation from an electron spiraling in a magnetoplasma and the influence of the ambient plasma on it are considered. It is pointed out that this influence is more important for the extraordinary mode ( $\mathrm{X}$-mode) than the ordinary mode ( $O$-mode). The appearance of the anomalous $X-m o d e$ with a narrow band and great radiation power can be expected.

Using the Lienard-Wiechert potentials, the electromagnetic fields by an accelerated electron are deduced. It is assumed in this paper that the ambient plasma which is homogeneous, cold, collisionless is immersed in a constant magnetic field, and the presence of ions may be neglected.

The resuits we have obtained are useful for the interpretation of some characteristics of the electromagnetic fields by a charged particle spiraling in the magnetic field of the sun, the Jupiter and in the geomagnetic field.

* The Influence of the Magnetoplasma on Gyro-Synchrotron Radiation

* Tadahiko OGAWA and Kunitomo SAKURAI (Ionosphere Research Laboratory, Kyoto University, Kyoto) 


\section{小川・桜井}

\section{1. 序 論}

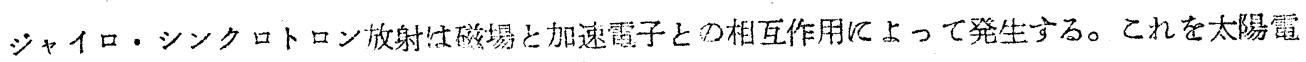

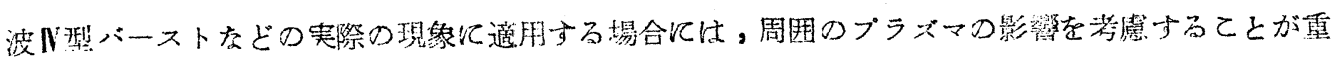

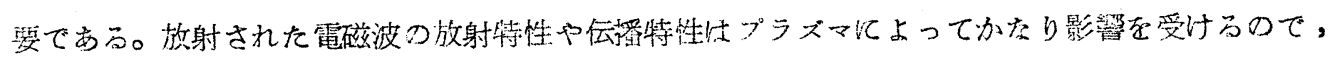
これを䁈視するととは適当で空いと思われる。

磁化プラズマ中和ける高速電子から発生するジイロ・シンクロトロン放射や，サイクロトロ

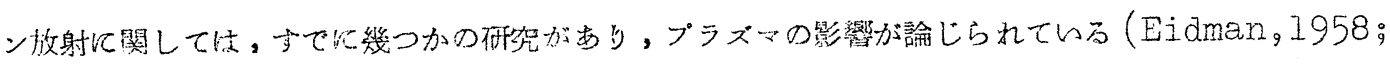
Liemohn, 1965; Nansfield, 1967; Ramaty and Lingenfelter, 1967)。

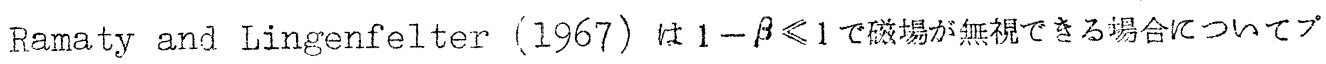

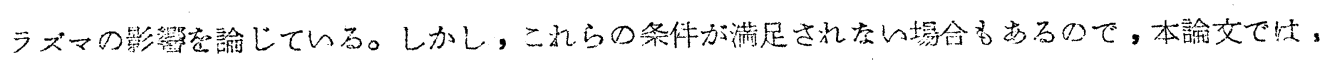

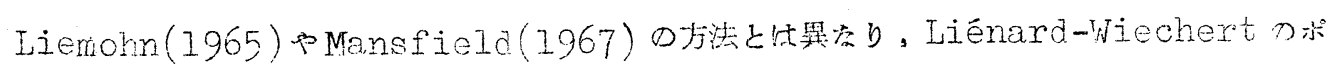
テンシャルを出発点てして、シャイロ・シンタロン敌射のエネルギースペクトルを論じる。計算結

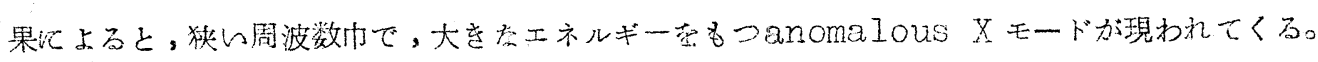

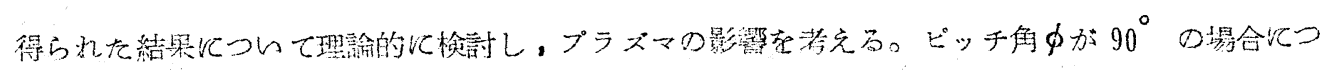

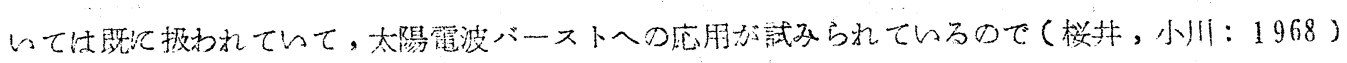
本諭交ては $\phi \neq 90^{\circ}$ の場合盁洘察吉る。

2. 磁化プラズマ中放けるシャイロ・シンクロトロン放射つ理䜊式つ導出

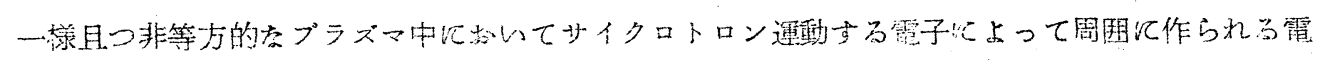

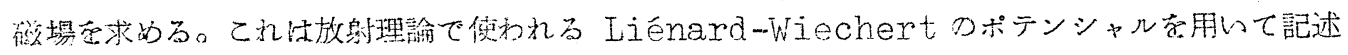

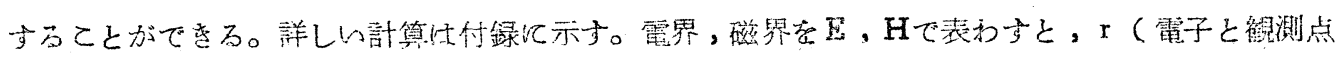

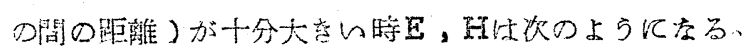

$$
\begin{aligned}
& \mathrm{E}=\mathrm{e} \frac{\mu^{2}(\mathrm{n} \cdot \dot{\vec{\beta}})(\mathrm{n}-\vec{\beta})-\mu \overrightarrow{\vec{\beta}}(1-\mu \mathrm{n} \cdot \vec{\beta})}{\mathrm{r} c(1-\mu \mathrm{n} \cdot \vec{\beta})^{3}} \\
& \mathrm{X}=\mu(\mathrm{n} \times \mathrm{E}) .
\end{aligned}
$$

但L

$\mu:$ プラズマの煀折率

$\mathrm{e}$ ：電子刀電荷 c：光速庶 


$$
\text { シャイロ・シンクロトロン放射记対する磁化プラズマの影篦 }
$$

$\mathrm{n}$ : ペクトル（ $\mathrm{r}=|\mathrm{r}|)$ の単位ベクトル

$\mathrm{v}$; 電子の速度ベクトル

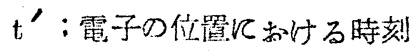

$$
\vec{\beta}=\frac{v}{\partial} \quad \vec{\beta}=\frac{\partial \vec{\beta}}{\partial t^{\prime}}
$$

(1)，(2)で $\mu=1$ と小くと，上く知られた真空中での電磁場わ式が得られら（Heitler，1954； Landau and Lifschitz，1961).。磁場中の電子は磁力線儿治って螺線運動をする。その 時のサイクロトロン角周波数 $\omega_{\mathrm{B}}$ は

$$
{ }^{\omega}{ }_{\mathrm{B}}=\omega_{\mathrm{H}} \sqrt{1-\beta^{2}} \quad \omega_{\mathrm{H}}=\frac{\mathrm{e} \mathrm{H}_{0}}{\mathrm{~m}_{0 \mathrm{c}}}
$$

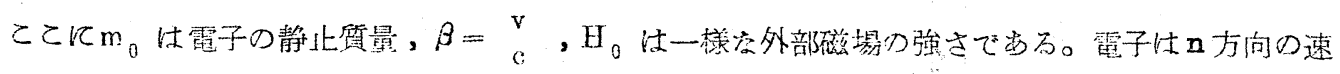

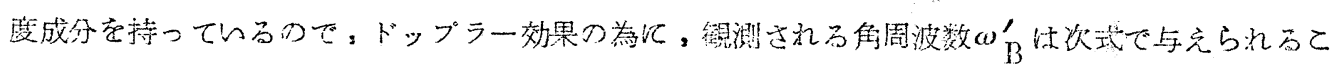
进左召。

$$
\omega^{\prime}{ }_{B}=\frac{{ }^{\omega} \mathrm{B}}{1-\mu \beta \cos \phi \cos \theta}
$$

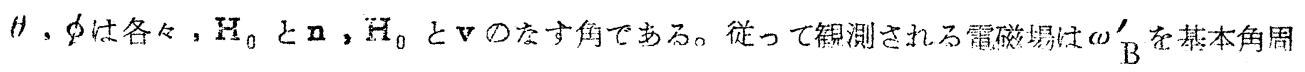

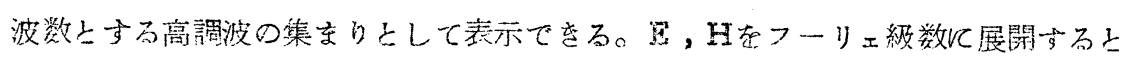

$$
\begin{aligned}
& \mathrm{E}, \mathrm{H}=\sum_{-\infty}^{\infty}\left(\mathrm{E}_{\mathrm{n}}, \mathrm{H}_{\mathrm{n}}\right) \mathrm{e}^{-\mathrm{in} \omega_{\mathrm{B}}^{\prime} \mathrm{t}} \\
& E_{n}, H_{n}=\frac{\omega_{B}^{\prime}}{\pi} \int_{0}^{\frac{2 \pi}{\omega_{B}^{\prime}}}(E, H) e^{i n \omega_{B}^{\prime} t} d t
\end{aligned}
$$

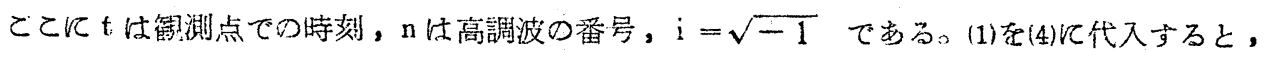
$E_{n}, E_{n}$ が得られる(詳細恃付録を参照)。 


\section{小刡・桵井}

$$
\begin{aligned}
& E_{n}=\frac{2 n e \omega_{B} \mu \beta \sin \phi}{c r(1-\mu \beta \cos \phi \cos \theta)^{2}} e^{i n \omega_{B}^{\prime} \mu \frac{\mathrm{r}}{\mathrm{c}}} \times \\
& \quad\left\{\mathrm{i} J_{\mathrm{n}}^{\prime}(\mathrm{x})+\mathrm{n} \frac{\mathrm{i}(1-\mu)}{\mu \beta \sin \phi} J_{\mathrm{n}}(\mathrm{x})+\mathrm{i} \times \mathrm{n} \frac{\mathrm{i}(\mu \beta \cos \phi-\cos \theta)}{\mu \beta \sin \phi \sin \theta} \mathrm{J}_{\mathrm{n}}(\mathrm{x})\right\} \\
& \mathrm{H}_{\mathrm{n}}=\mu\left(\mathrm{n} \times \mathrm{E}_{\mathrm{n}}\right) \\
& \mathrm{x}=\frac{\mathrm{n} \mu \beta \sin \phi \sin \theta}{1-\mu \beta \cos \phi \cos \theta}
\end{aligned}
$$

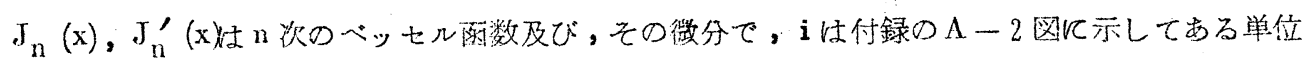
ベクトルである。(5)，(6)上り，n番目わ高調波のn方向の単位立体角あたりの放射強度 $\mathrm{S} n$ 壮ポ

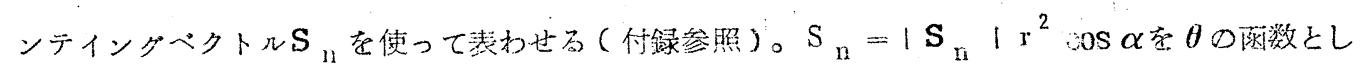
て表わすと，

$$
\begin{aligned}
& S_{n}(\theta)=\frac{(n \circ \omega B)^{2} \mu}{2 \pi c(1-\mu \beta \cos \phi \cos \theta)^{4}} \sqrt{\frac{1}{1+\tan ^{2} \alpha}} \times \\
& {\left[\left\{\left(\mu \beta \sin \phi J_{n}^{\prime}(x)\right)^{2}+\left\{\frac{\mu \beta \cos \phi-\cos \theta}{\sin \theta} J_{n}(x)\right)^{2}\right\}^{2}\right.} \\
& \left.+\left\{\frac{(1-\mu)(\mu \beta \cos \phi-\cos \theta)}{\sin \theta}:\left(J_{n}(x)\right)^{2}\right\}^{2}\right\}^{1 / 2}
\end{aligned}
$$

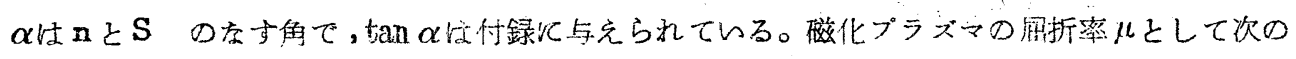
Appleton-Hartree の式使用一る。

$$
\mu^{2}=1-\frac{\frac{\omega_{\mathrm{p}}^{2}}{\omega^{2}}}{1-\frac{\left.\frac{\left({ }^{\omega} \mathrm{H}\right.}{\omega} \sin \theta\right)^{2}}{2\left(1-\frac{\omega_{\mathrm{p}}^{2}}{\omega^{2}}\right)} \pm \sqrt{\frac{\left(\frac{\omega_{H}}{\omega} \sin \theta\right)^{2}}{4\left(1-\frac{\omega_{\mathrm{p}}^{2}}{\omega^{2}}\right)^{2}}+\left(\frac{\omega_{\mathrm{H}}}{\omega} \cos \theta\right)^{2}}}
$$




\section{シャイロ・シンクロトロン放射に対する磁化プラズマの影響}

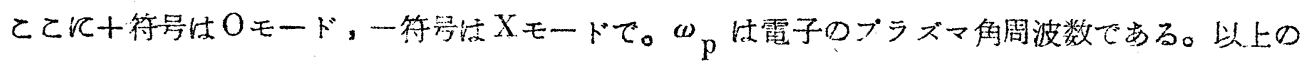
計算過程で明らかなよに，本諭文で㤌次の仮定をしている。

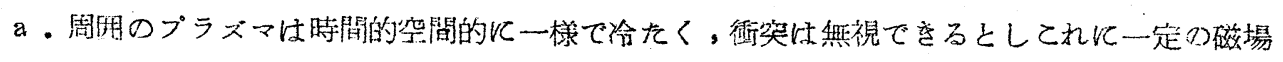
H。が加えられている。

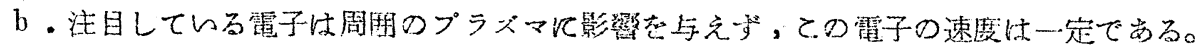

○.イオンの影響䄈禎する。

以前からら，磁化プラズマ中でのサイクロトロン放射は多くの人々によって研究されている。放射

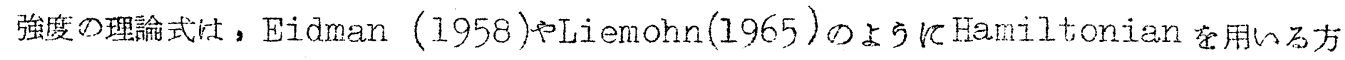

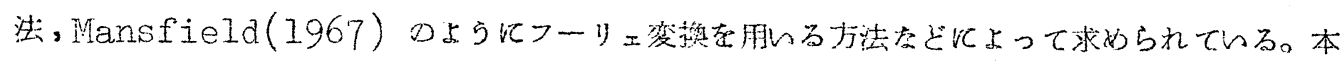

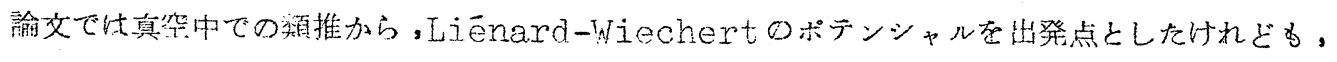

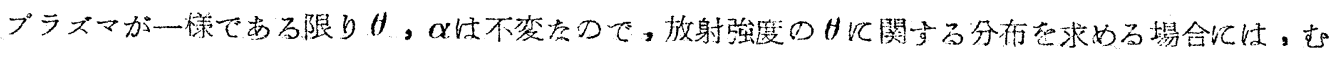

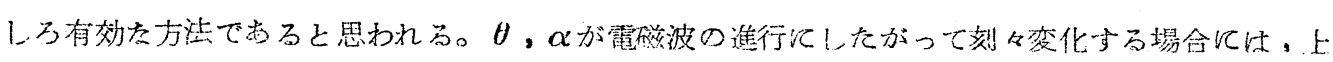

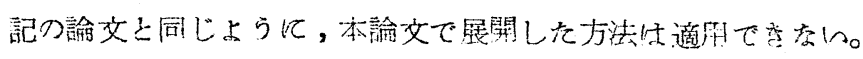

\section{3. 放射強度の計算結果と理䜽的検討}

\section{1 計算結果}

$\mathrm{n}$ 番目の高調波つ角周波数(1)昍(3)上り

$$
\begin{aligned}
& \omega=\mathrm{n} \omega_{\mathrm{B}}^{\prime}=\frac{\mathrm{n} \omega_{\mathrm{B}}}{1-\mu \beta_{\|} \cos \theta} \\
& \beta_{\|}=\beta \cos \phi
\end{aligned}
$$

で与えられる。(9)をAppleton-Hartree の式(8)亿入れて，(8)，(9)を同時满たす屈折率化 求かる必婆がある。この メーターとするのの函数として求支る。例として $\mathrm{H}_{0}=100$ ガウス, 電子密度 $\mathrm{N}_{\mathrm{e}}=10^{9} / \mathrm{cm}^{3}$, $\phi=15^{\circ}, 45^{\circ}, 80^{\circ} \quad \beta=0.5,0.8,0.9$ と選び， $\theta, \beta, \phi$ をパラメーターとするいと $\mathrm{S}_{\mathrm{n}}(\theta)$

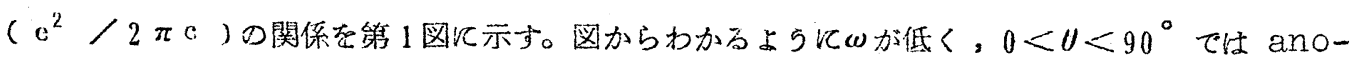

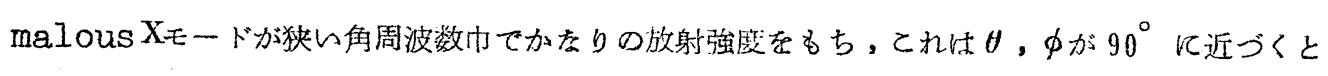

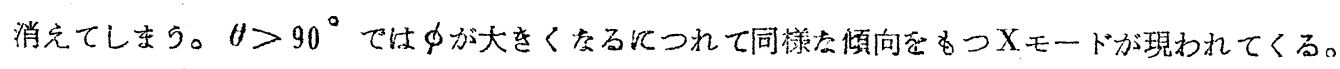


小川・桜井

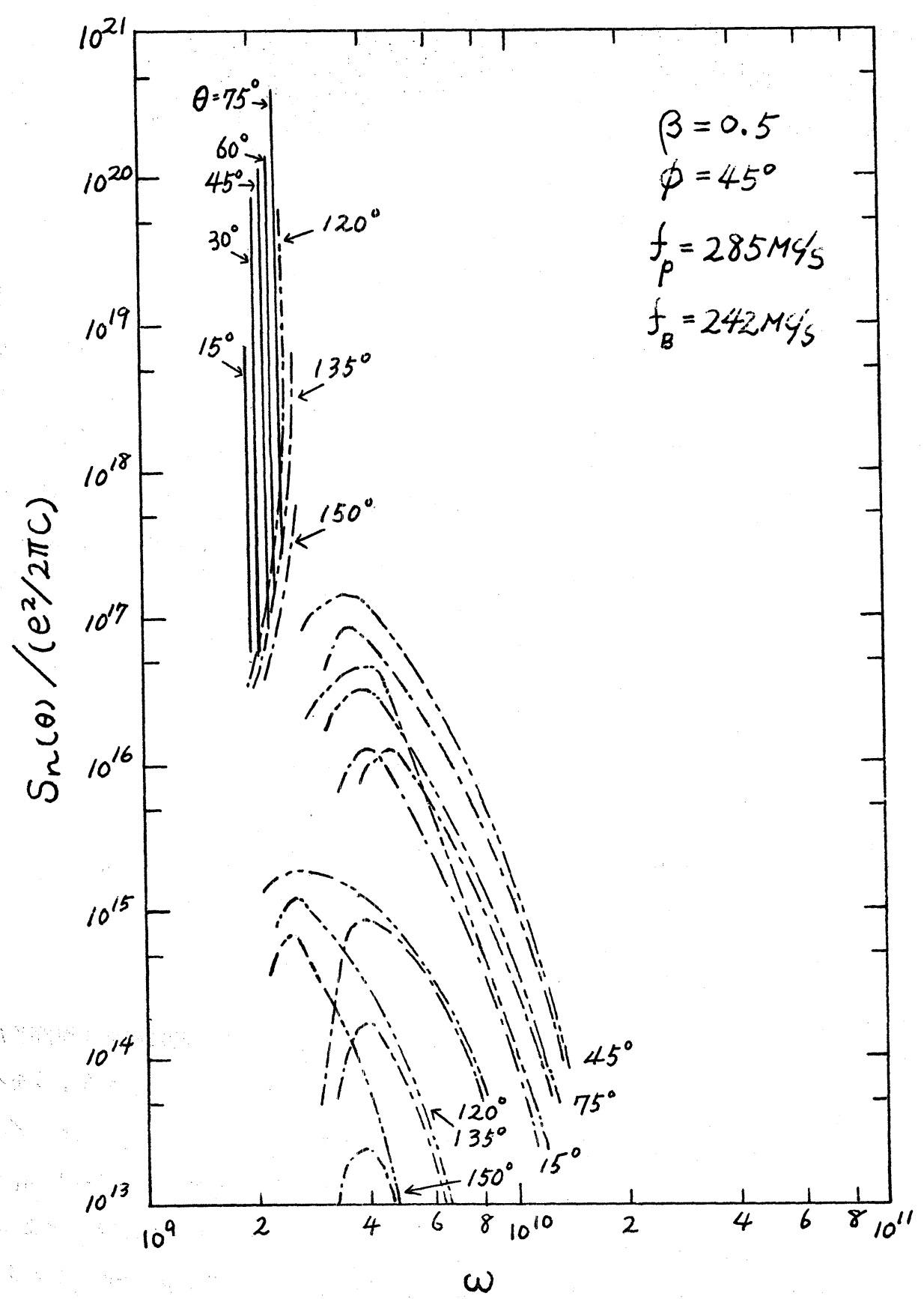

第 1 図(a) 
ジャイロ・シンクロトロン放射に対する磁化ブラズマの影響

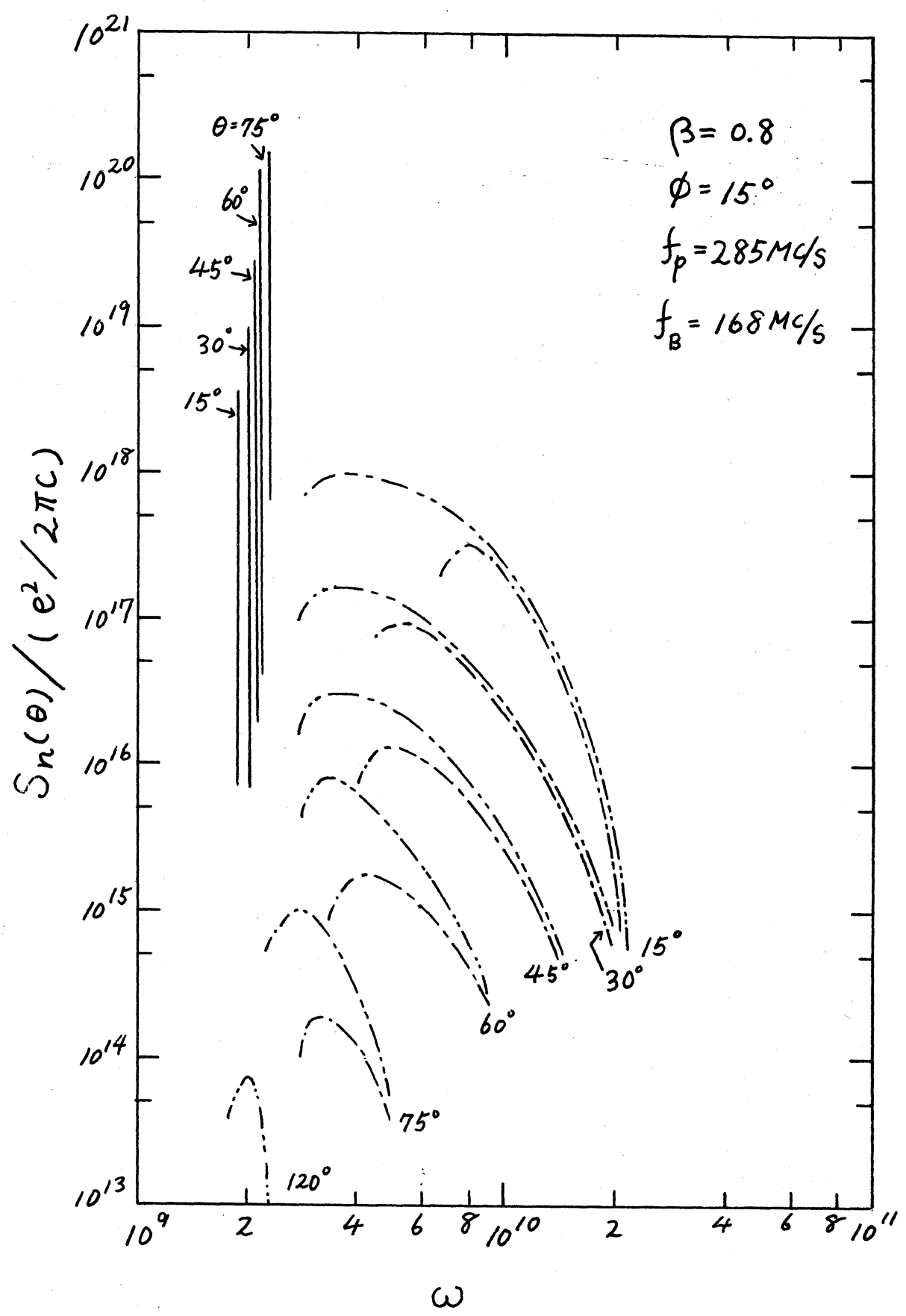

第 2、図(b) 
小川・桜井

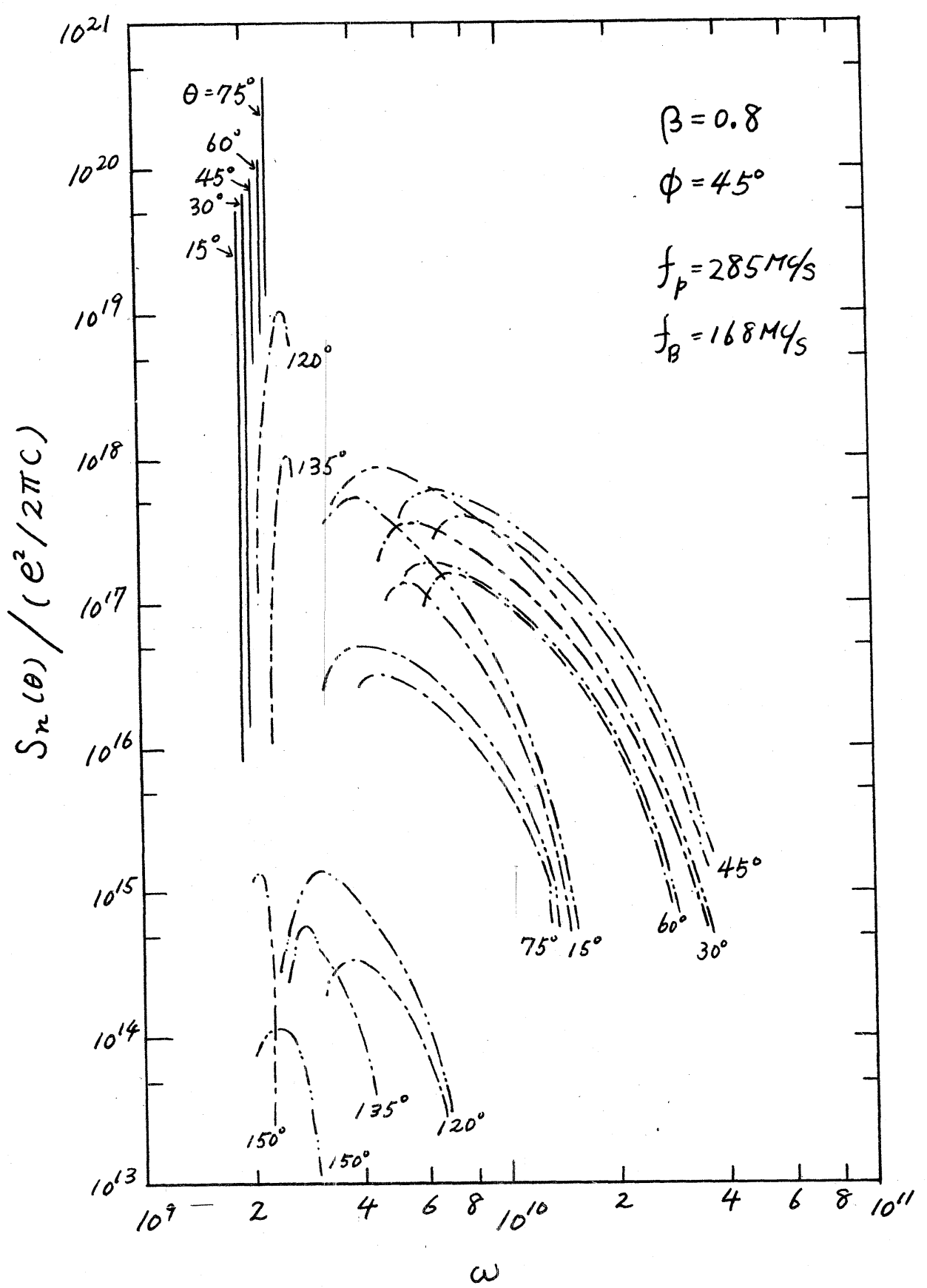

第 1 図 (c) 


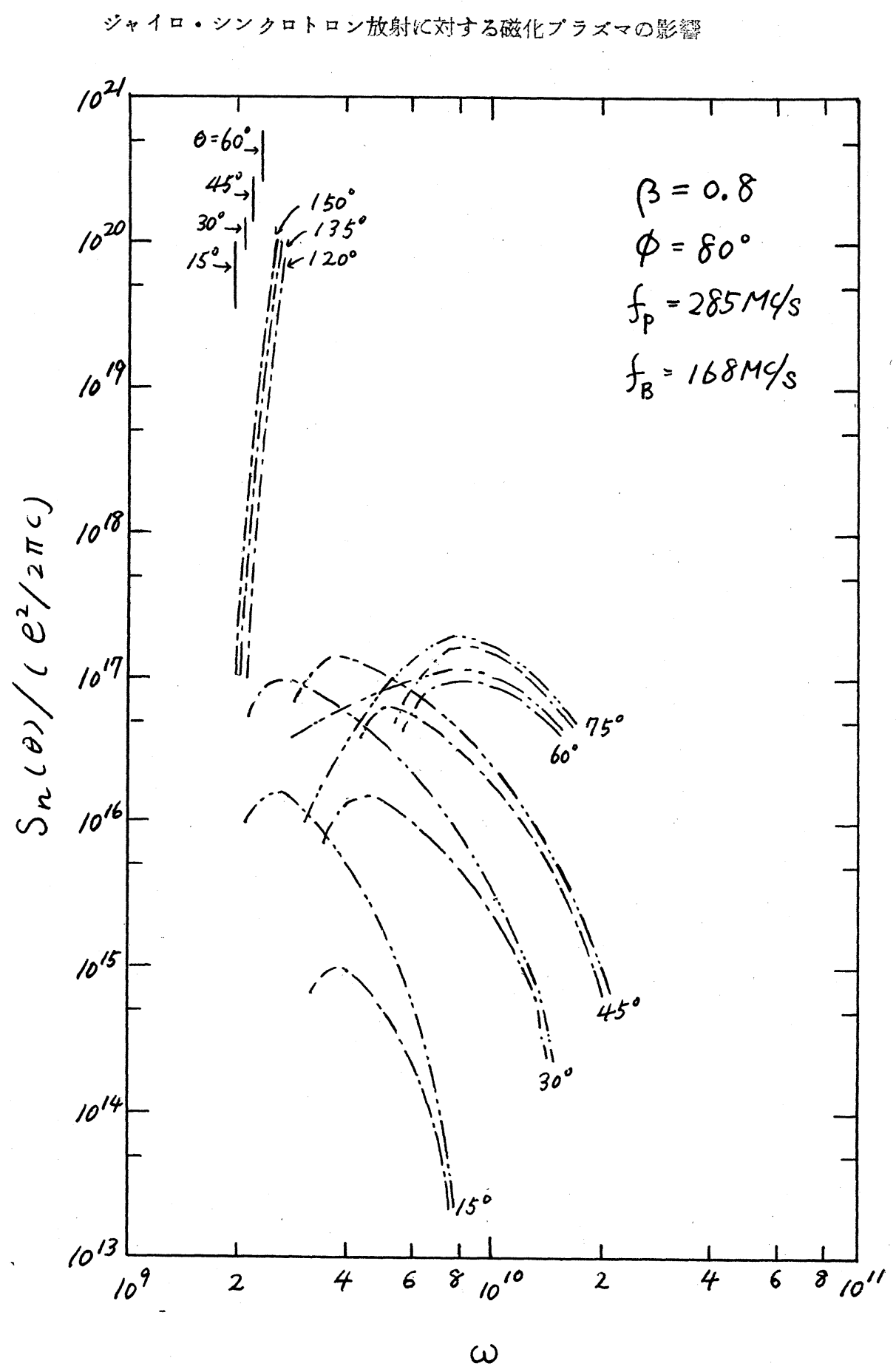

第 1 図 (d) 
小川・桜井

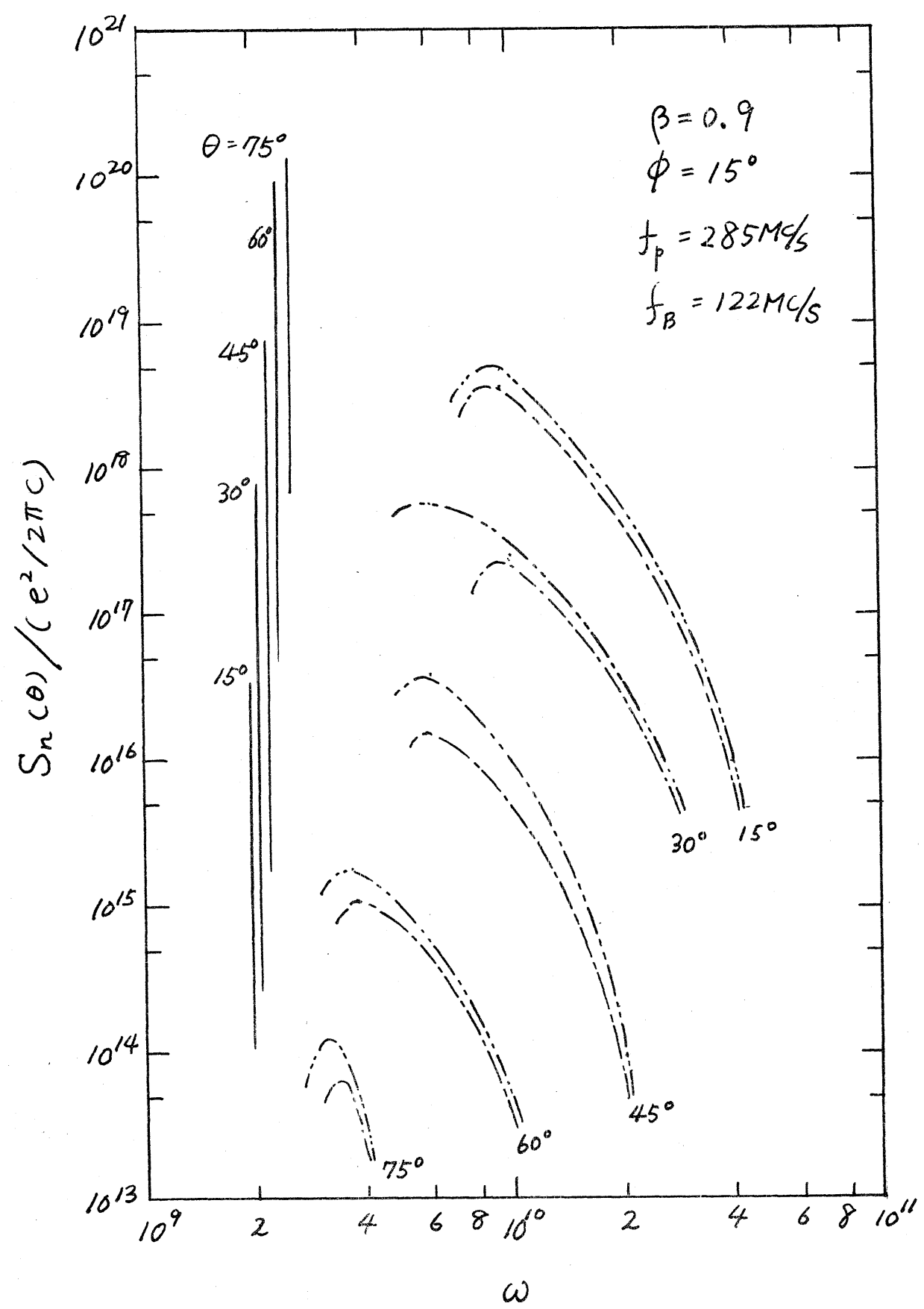

第 1 図(e) 
ジャイロ・シンクロトロン放射に対する磁化プラズマの影響

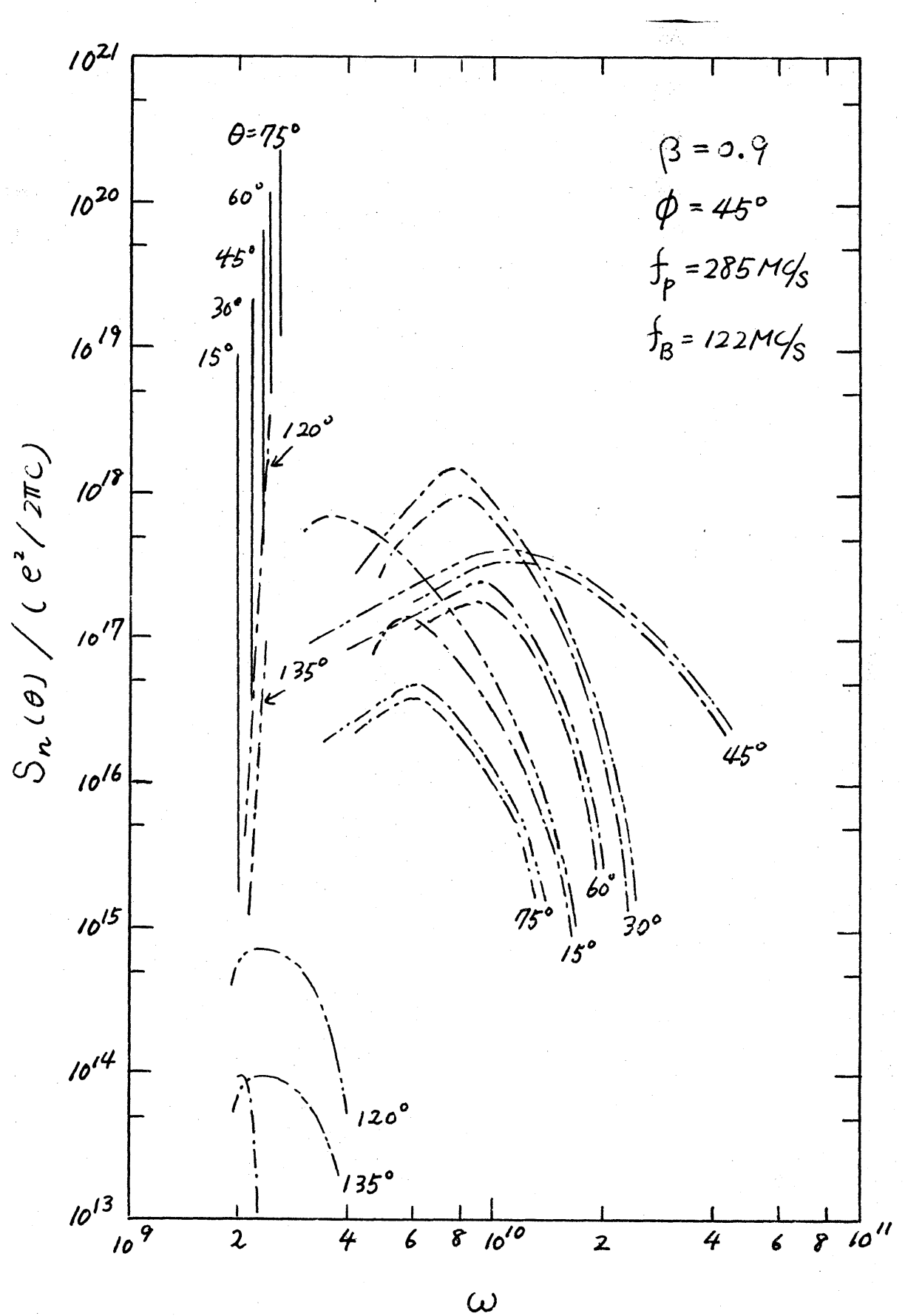

第 1 図 (f) 


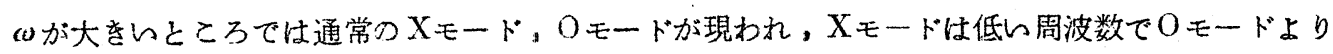

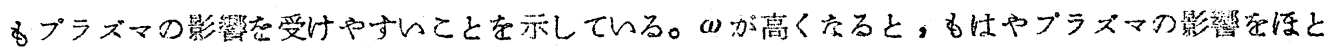

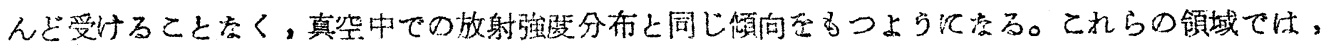

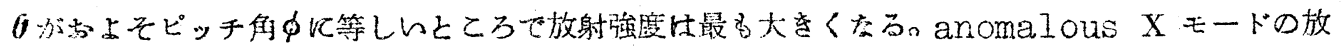
射強度の最大が $\beta=0.5 \sim 0.9$ の間飞的て $10^{19} \sim 10^{20}$ のオーダーであるととは興時深い。この值

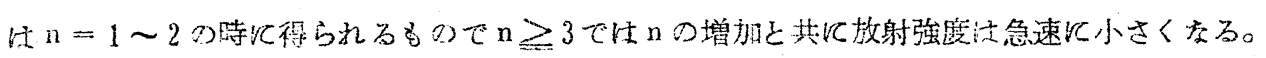

\section{2 理論的㭘誩}

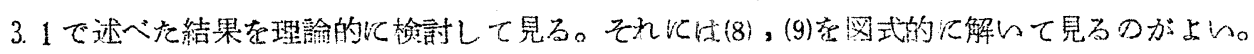

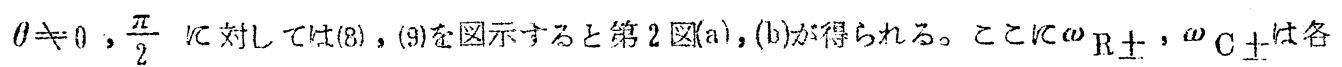

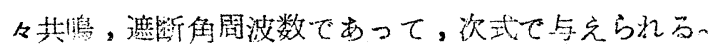

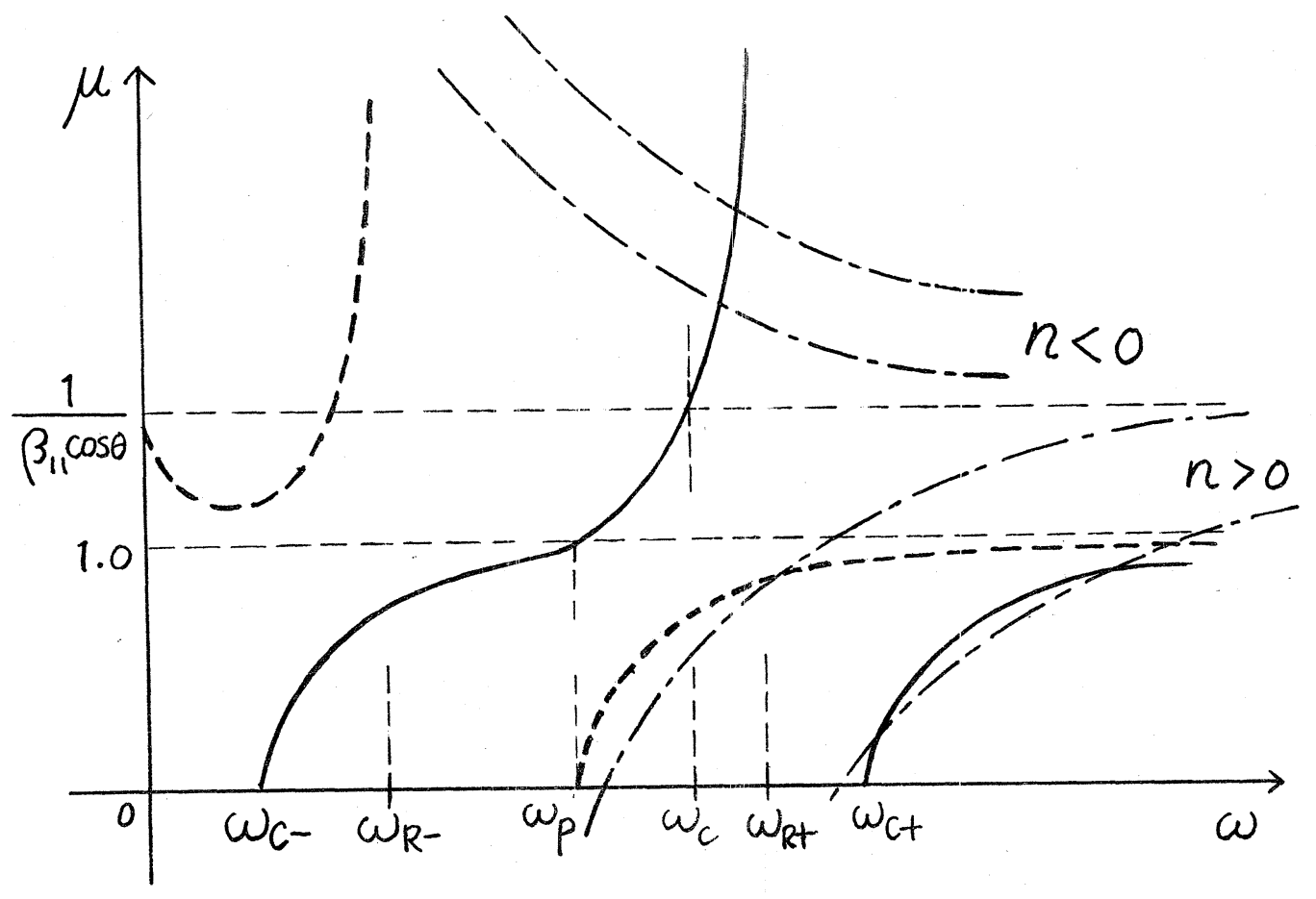

第 2 図 (a) 


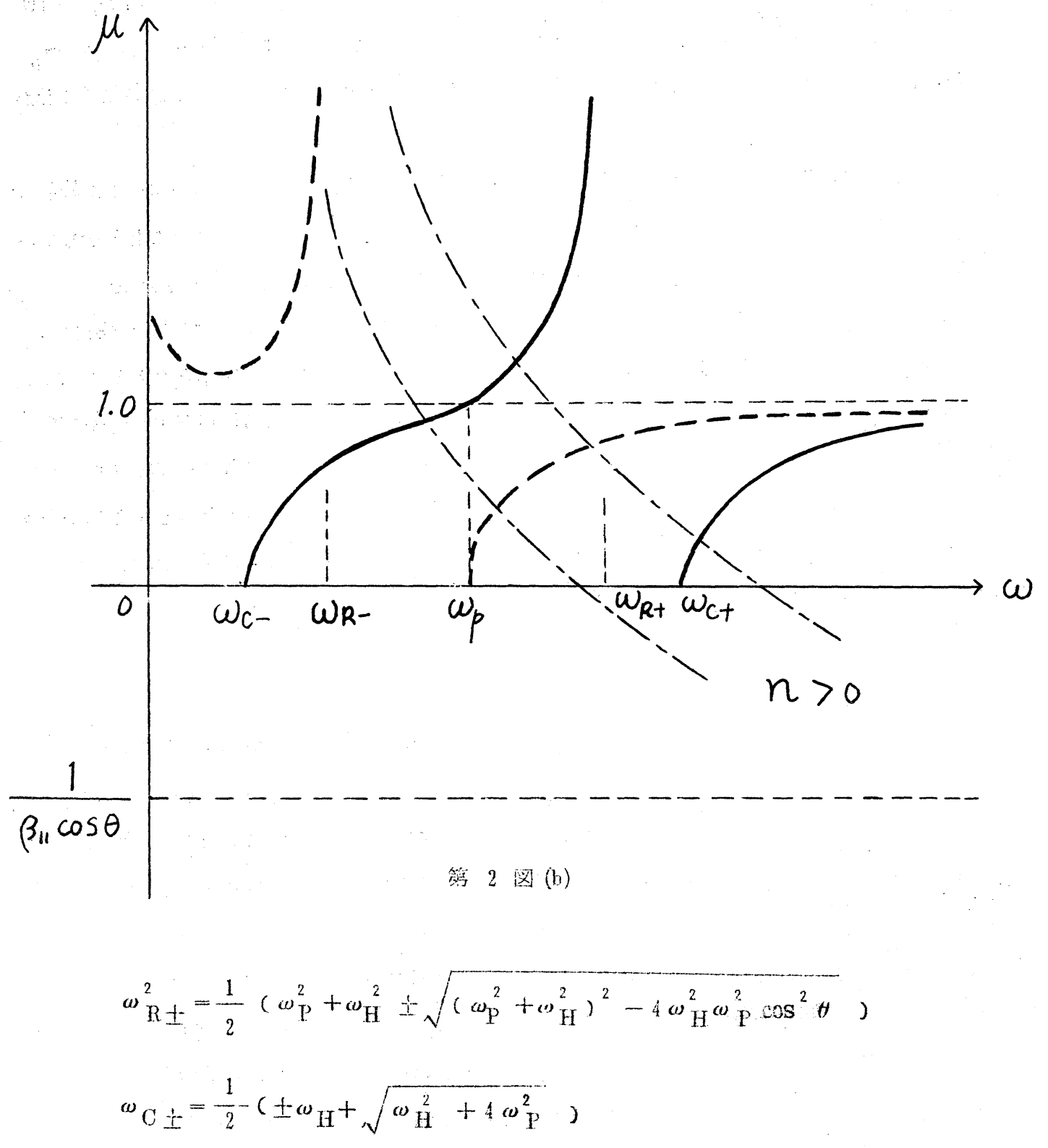

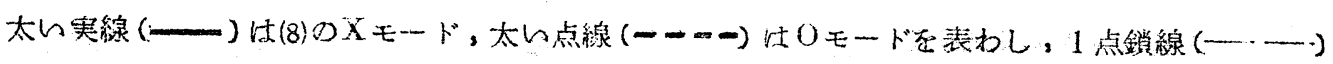

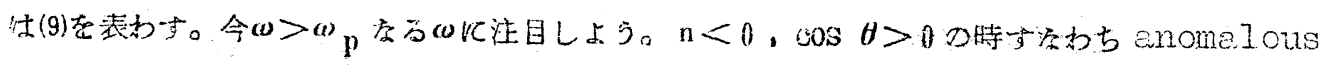


小惊井

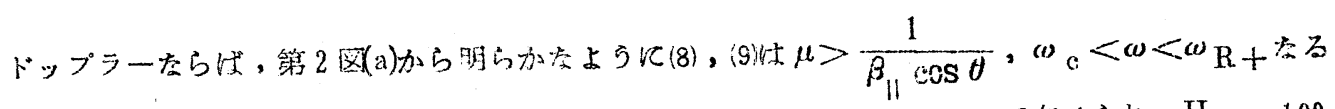

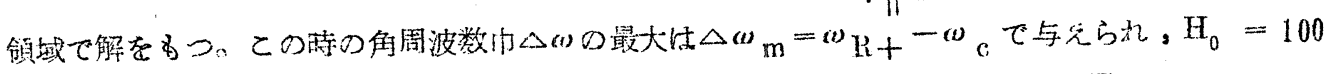

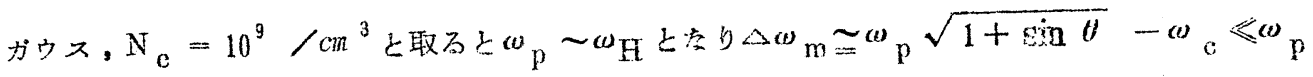

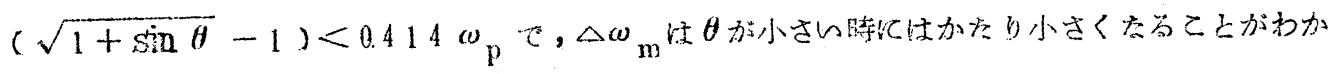
bo

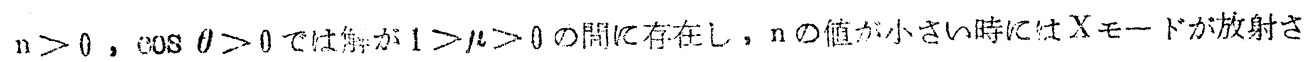

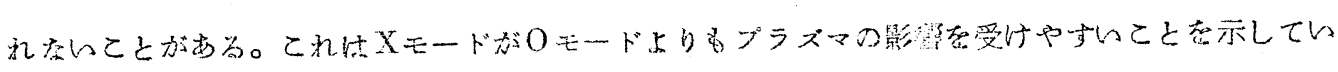

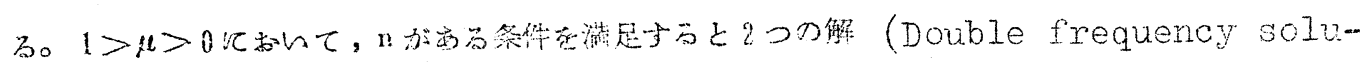

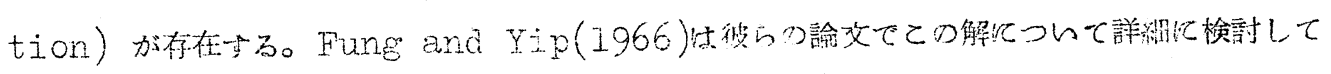

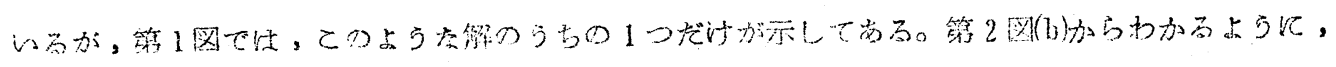

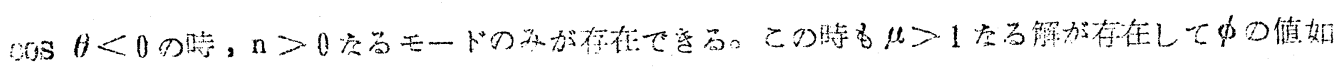

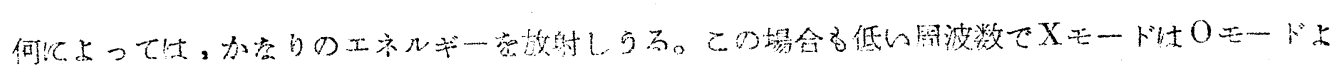

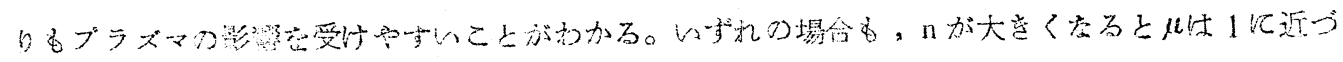

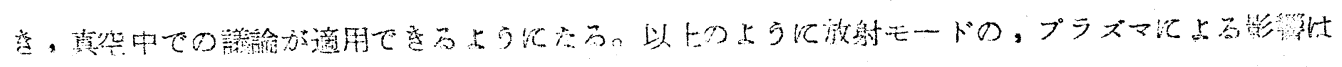

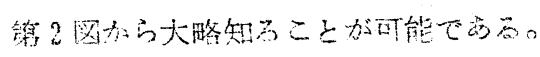

4. 結馀

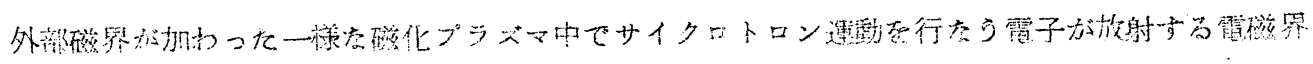

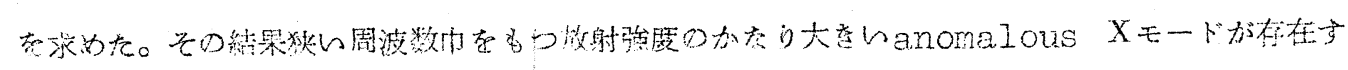

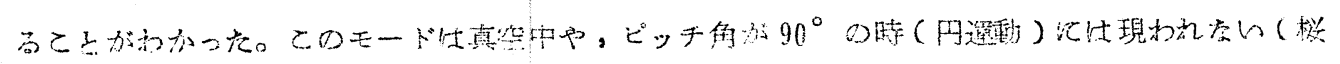

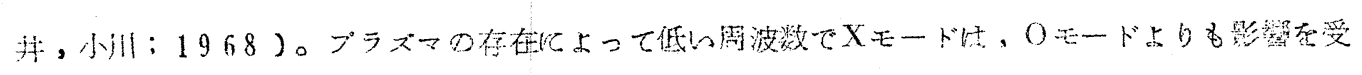
Hermo

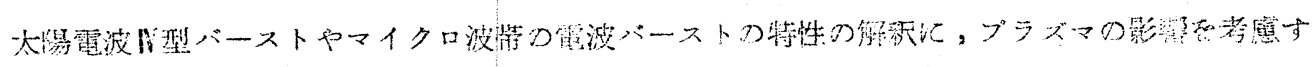

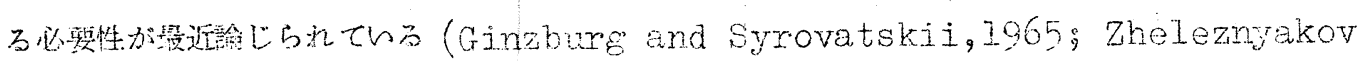
and Trakhtengerts, 1966; Romaty and Lingenfelter, 1967:Yip, 1967)。

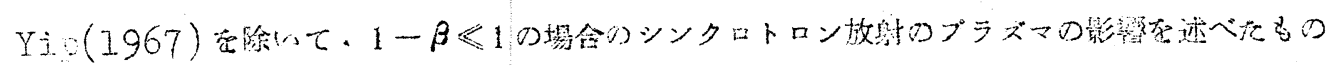

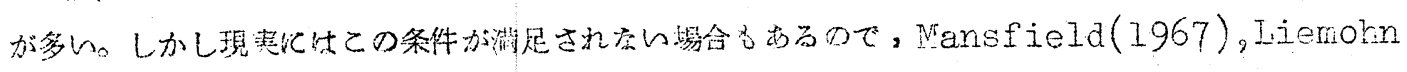

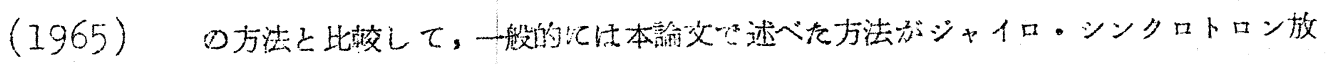

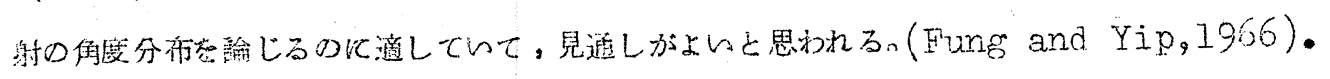




$$
\text { シャイロ・シンクロトロン放的に対する磁化プラズマの影響 }
$$

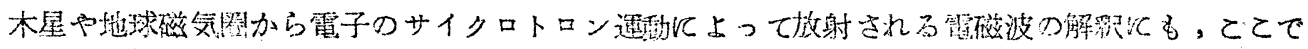

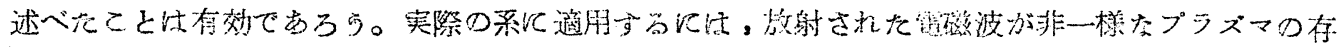

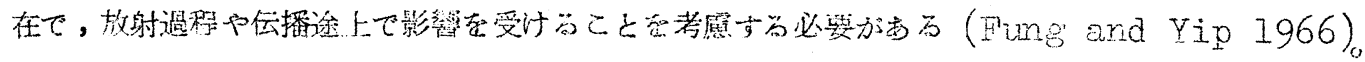

文献

Eidman, V.Ia., Soviet Fhys. -J.E.T.P., 34, 91 (1958).

Fung, P.C.W. and Yip, W.K., Aust. J. Phys., 19, 759 (1966).

Ginzburg, V.I. and Syrovatskii, S.I., Ann. Rev. Astron.

$$
\text { Astrophys., 2. } 297 \text { (1965). }
$$

Heitler, W., The Quantum Theory of Radiation, 3rd. ed.,

Clarendon, Oxford (1954).

Landau, I. and Lifschitz, E., The Classical Theory of Field, Fergamon, New York (1961).

Liemohn, U.B., Radio Sci., 69D, 741 (1965).

Mansfiela, V.I., Astrophys. Jo, 147, 672 (1967)。

Ramaty, R. and Lingenfelter, R.E., J. Geophys. Res. 72 , 879 $(1967)$.

桜井,小川，核融合研究， $20, N 0.4$ ( 1968).

Yip, W.K., Aust. J. Phys., 20, 421 (1967). 


\section{小川・就牛}

付録 一様奆磁化プラズマ中を通勳する加速霞子つ作る 電磁罚们幥出

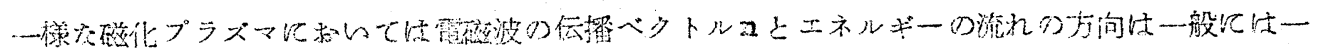

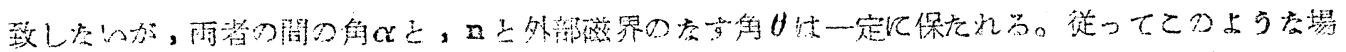

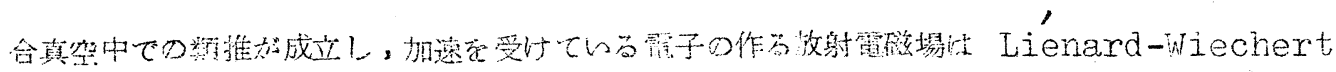

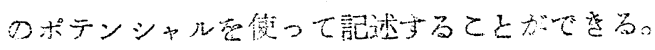

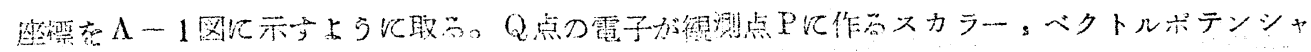

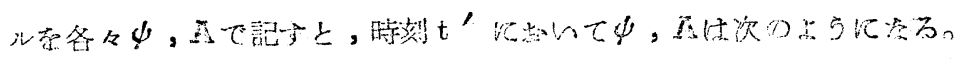

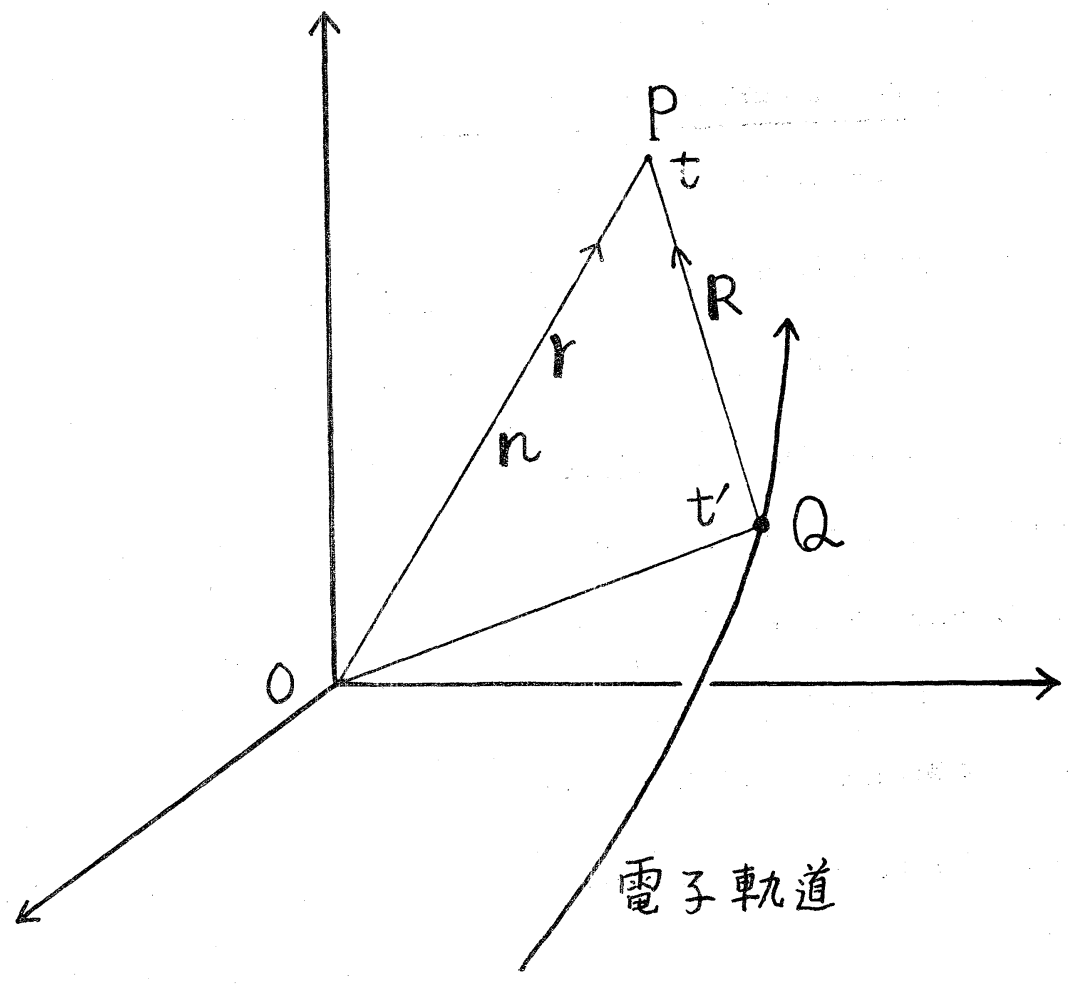

A -1 沧 


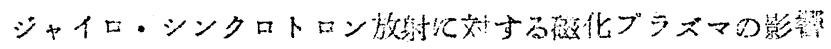

$$
\begin{aligned}
& \phi=-\left.\frac{c}{R-\frac{v \cdot I}{C^{\prime}}}\right|_{t^{\prime}} \quad A=\frac{e v}{C^{\prime}\left(R-\frac{v \cdot R}{C^{\prime}}\right)} t^{\prime} \quad(A-1)
\end{aligned}
$$

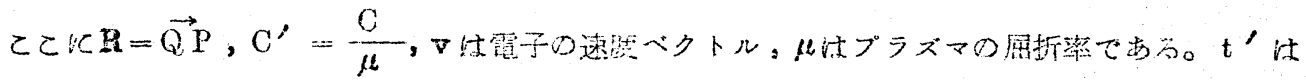

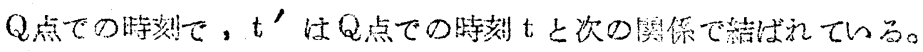

$$
\mathrm{t}^{\prime}+\frac{\mathrm{I}\left(\mathrm{t}^{\prime}\right)}{\mathrm{C}^{\prime}}=\mathrm{t} \quad(\mathrm{A}-2)
$$

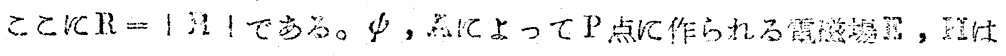

$$
\begin{array}{ll}
E=-\frac{1}{\sigma} \frac{\partial Z}{\partial t}-\nabla \psi^{\prime \prime} & (A-3) \\
Z=\nabla \times A & (A-4)
\end{array}
$$

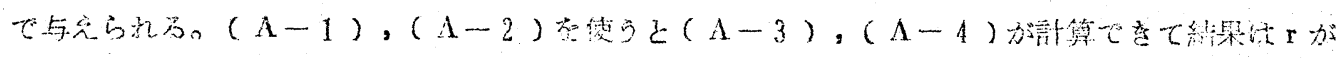

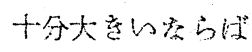

$$
\begin{aligned}
& \mathbb{E}=\mathrm{c} \frac{\mu^{2}(\mathrm{n} \cdot \dot{\vec{\beta}})(\mathrm{n}-\overrightarrow{\vec{\beta}})-\mu \dot{\vec{\beta}}(1-\mu \mathrm{n} \cdot \vec{\beta})}{\mathrm{r} c(1-\mu \mathrm{n} \cdot \hat{\beta})^{3}} \\
& P=\mu(n \times n) \\
& (A-5) \\
& (A-6)
\end{aligned}
$$

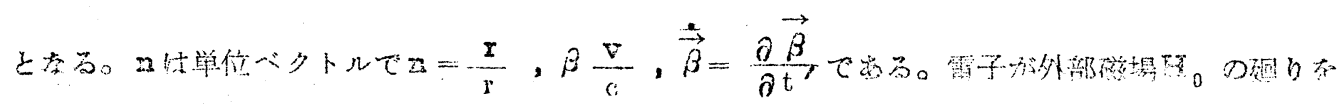

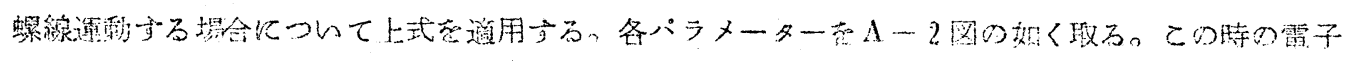
のサイクロトロン角周波数( B计

$$
\omega_{\mathrm{B}}=\omega_{\mathrm{H}} \sqrt{1-\beta^{2}} \quad \omega_{\mathrm{H}}=\frac{e \mathrm{H}_{0}}{m_{0} \mathrm{c}} \quad \beta=\frac{|\mathrm{v}|}{a}
$$

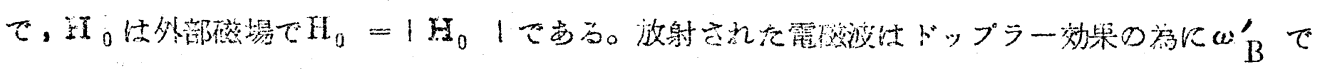

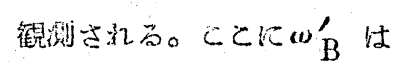

$$
\omega_{B}^{\prime}=\frac{\omega_{B}}{1-\mu \beta \cos \phi \cos \theta}
$$


小川・粰井

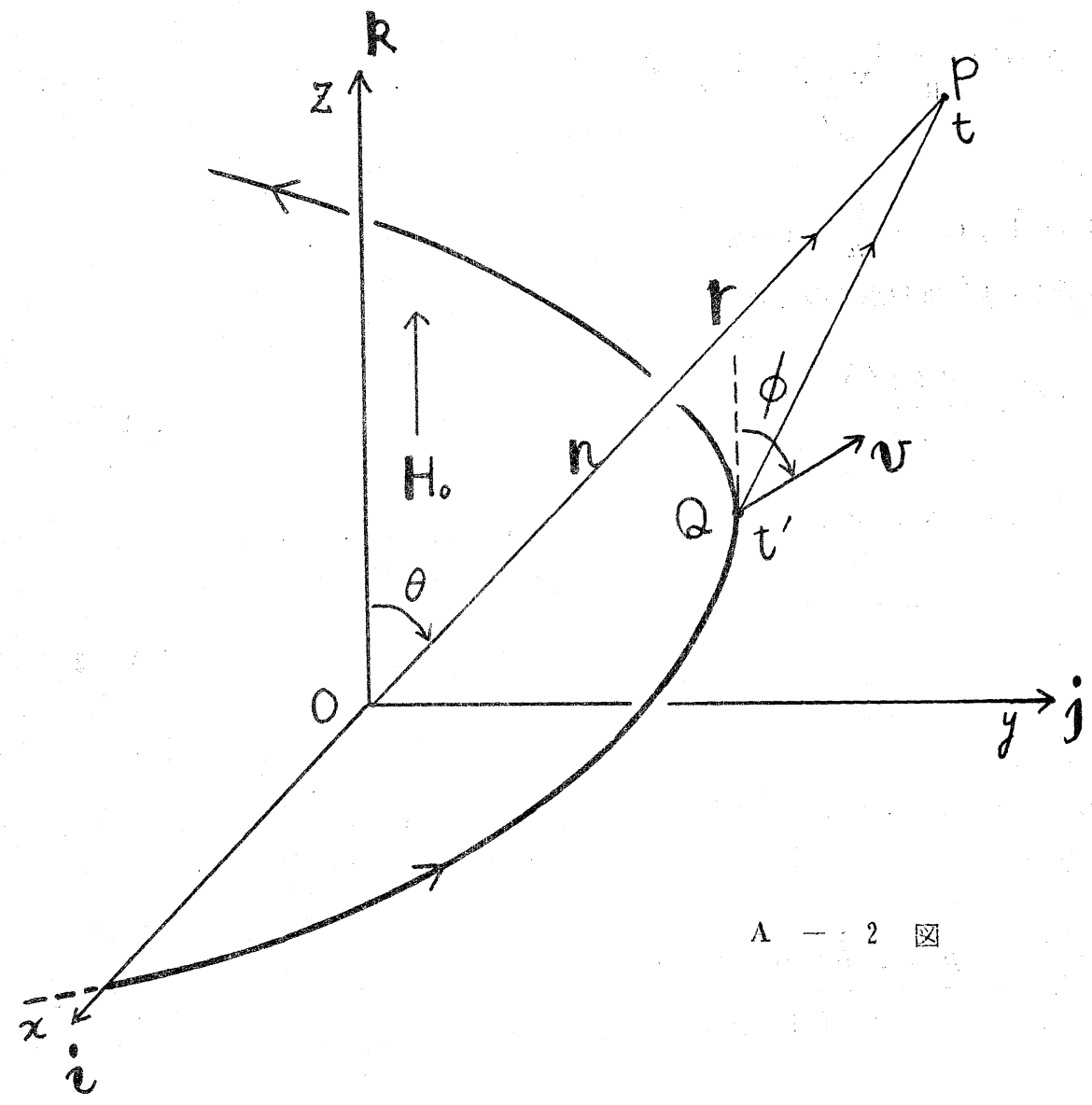

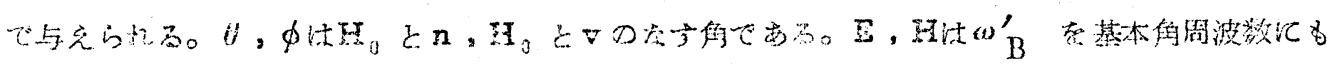

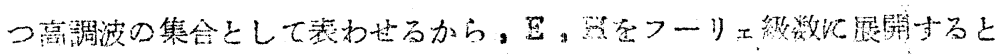

$$
\begin{aligned}
& \mathbb{Z}, \mathrm{H}=\sum_{-\infty}^{\infty}\left(\mathbb{E}_{\mathrm{n}}, \mathrm{H}_{\mathrm{n}}\right) \mathrm{e}^{-\mathrm{in} \omega_{B}^{\prime}} \\
& (A-7)
\end{aligned}
$$

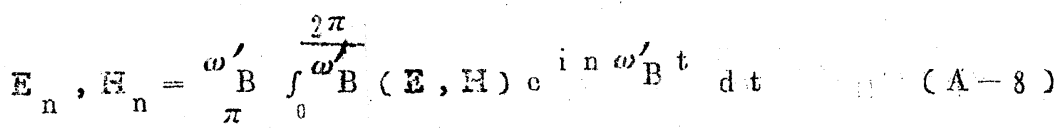

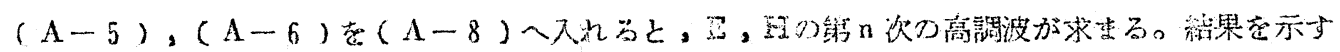
上
} 


$$
\begin{aligned}
& \text { シャイロ・シンクロトロン放纣他対す万磁化プラズマの影裙 } \\
& \mathbb{E}_{\mathrm{n}}=\frac{2 \mathrm{ne \omega} \mathrm{B} \mu \beta \sin \phi}{\operatorname{cr}(1-\mu \beta \cos \phi \cos \theta)^{2}} \mathrm{e}^{\mathrm{inc} \omega_{\mathrm{B}}^{\prime} \mu^{\frac{\mathrm{r}}{c}}} \times \\
& \left\{i J_{n}^{\prime}(x)+n \frac{i(1-\mu)}{\mu \beta \sin \phi} J_{n}(x)+i \times n \frac{i(\mu \beta \cos \phi-\cos \theta)}{\mu \beta \sin \phi \sin \theta} J(x)\right\} \quad(\Lambda-9) \\
& \mathrm{H}_{\mathrm{n}}=\mu\left(\mathrm{n} \times \mathrm{Z}_{\mathrm{n}}\right) \\
& (A-10) \\
& \mathrm{x}=\frac{\mathrm{n} \mu \beta \sin \phi \sin \theta}{1-\mu \beta \cos \phi \cos \theta}
\end{aligned}
$$

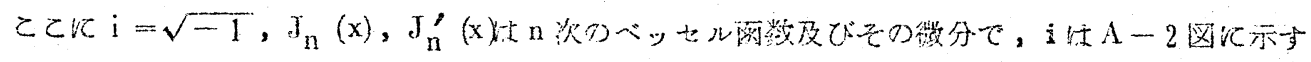

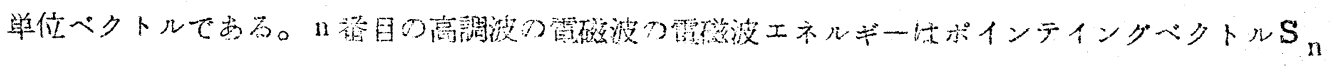

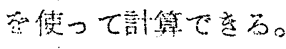

$$
S_{n}=\frac{c}{16 \pi}\left(B_{n}^{*} \times H_{n}+z_{n} \times H_{n}^{*}\right) \quad(A-11)
$$

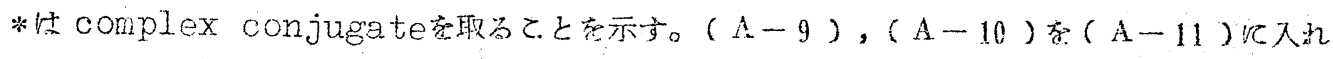

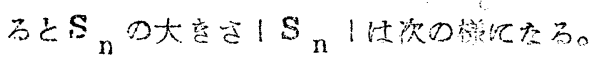

$$
\begin{aligned}
& \left|s_{n}\right|=\frac{(n c \omega B)^{2} \mu}{2 \pi c r^{2}(1-\mu \beta \operatorname{sos} \phi \cos \theta)^{4}}\left[\left\{\left(\mu \beta \sin \phi J_{n}^{\prime}(x)\right)^{2}+\left(\frac{\mu \beta \cdot O S \phi-\theta s \theta}{\sin \theta} J_{n}(x)\right)^{2}\right\}^{2}\right. \\
& \left.+\left\{\frac{(1-\mu)(\mu \beta \cos \phi-\sin \theta)}{\sin \theta}\left(J_{n}(x)\right)^{2}\right\}^{2}\right\}^{1 / 2}
\end{aligned}
$$

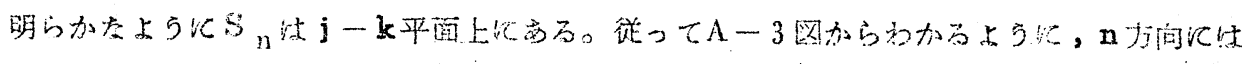

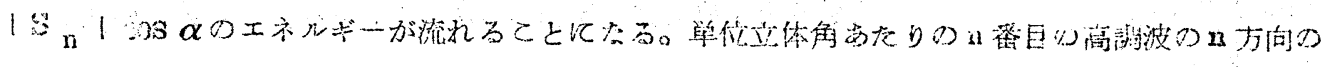

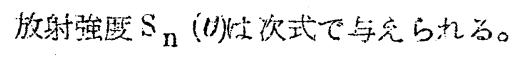

$$
S_{n}(t)=1 S_{n}\left|r^{2} \cos \alpha=1 S_{n}\right| r^{2} \sqrt{\frac{1}{1+\tan ^{2} \alpha}}
$$




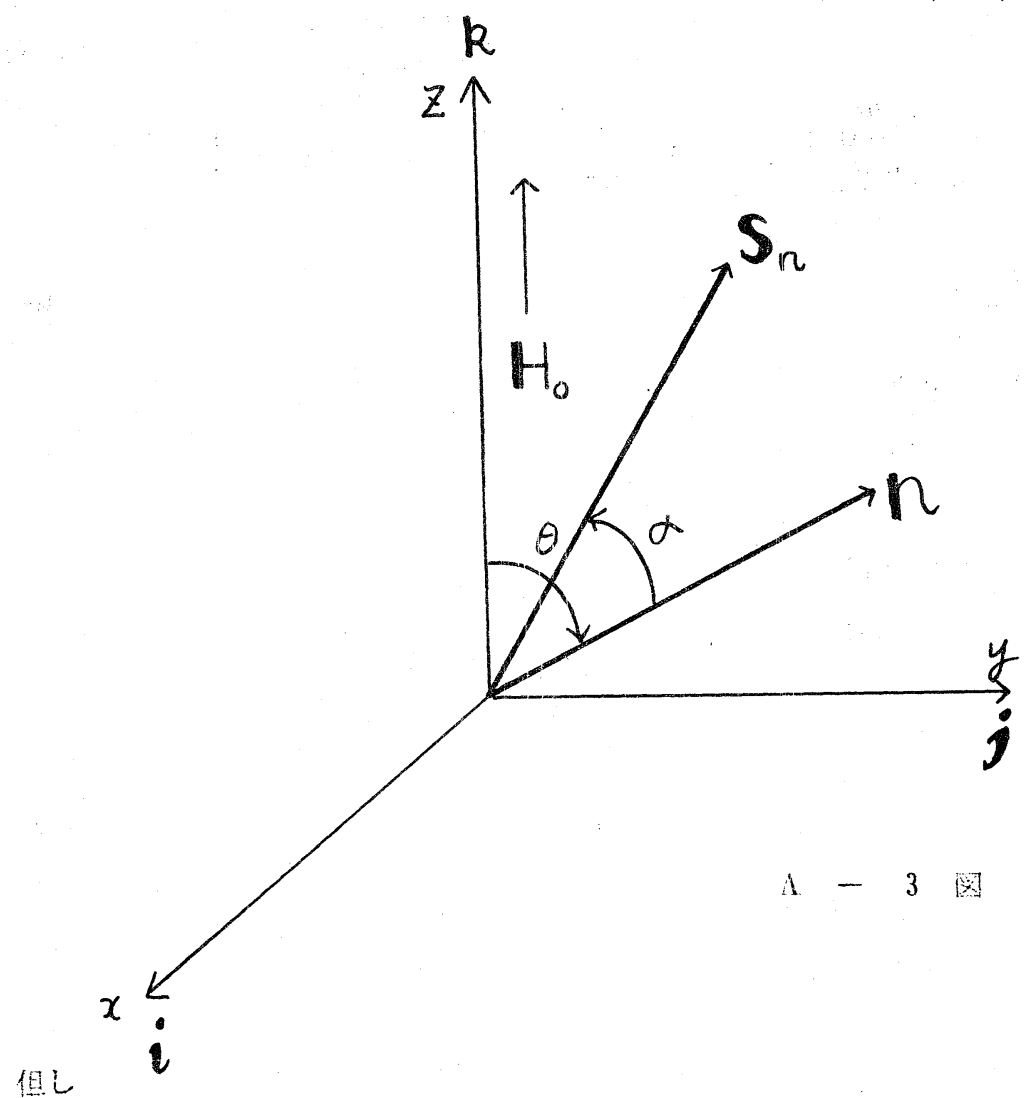

但L

$$
\operatorname{sen} \alpha=\frac{\frac{(\mu-1)(\mu \beta \cos \theta-\cos \theta)}{\sin \theta}\left(J_{n}(x)\right)^{2}}{\left(\mu \beta \sin \phi J_{n}^{\prime}(x)\right)^{2}+\left(\frac{\mu \beta \cos \phi-\cos \theta}{\sin \theta} J_{n}(x)\right)^{2}}
$$

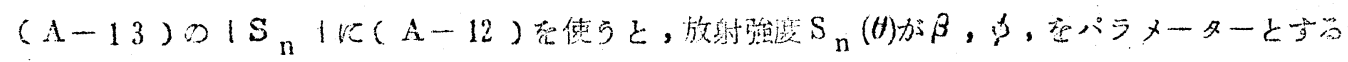
aの函溦として得られる。 


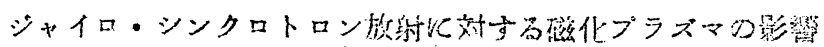

付図の説明

领1圈 角周搌数

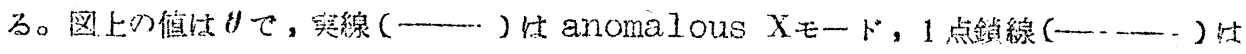

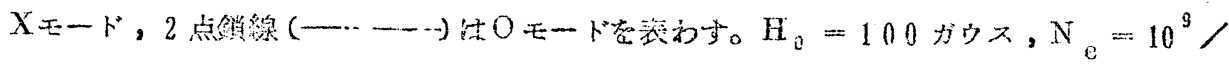
$c m^{3} \tau, f_{p}=\frac{{ }^{\prime \prime}}{2} \frac{p}{2 \pi}, f_{B}=\frac{\omega}{2 \pi}$ であ。
(a) $\beta=0.5, \phi=45^{\circ}, f_{p}=285 \mathrm{M} / \mathrm{f}_{\mathrm{B}}=242 \mathrm{M} \%$
(b) $\beta=0.8, \phi=15^{\circ}, \mathrm{f}_{\mathrm{p}}=285 \mathrm{M} / \mathrm{s}, \mathrm{f}_{\mathrm{B}}=168 \mathrm{M} \%$
(c) $\beta=0.8, \delta=45^{\circ}, f_{p}=285 \mathrm{M} \%, \mathrm{f}_{B}=168 \mathrm{M} \%$
(d) $\beta=08, \gamma=80^{\circ}, f_{p}=285 \mathrm{M} \%, f_{B}=168 \mathrm{M} \%$
(c) $\beta=09, \phi=15^{\circ}, \mathrm{f}_{\mathrm{p}}=285 \mathrm{M} / \mathrm{S}, \mathrm{f}_{\mathrm{B}}=122 \mathrm{M} \%$
(f) $\beta=0.9, \phi=45^{\circ}, f_{p}=285 \mathrm{M} / \mathrm{f}_{B}=122 \mathrm{M} \%$

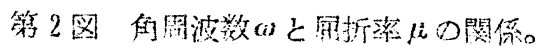

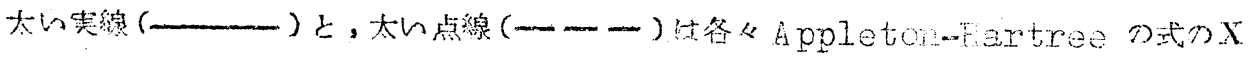

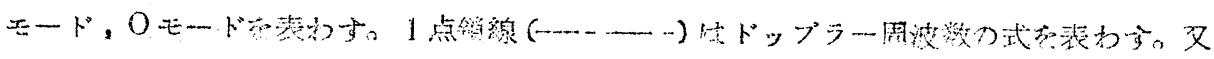

$$
\begin{aligned}
& \omega_{\mathrm{R} \pm}^{2}=\frac{1}{2}\left(\omega_{\mathrm{p}}^{2}+\omega_{\mathrm{H}}^{2} \pm \sqrt{\left.\left(\omega_{\mathrm{p}}^{2}+\omega_{\mathrm{H}}^{2}\right)^{2}-4 \omega_{H}^{2} \omega_{\mathrm{p}}^{2} \cos ^{2} \theta\right)}\right. \\
& \omega_{\mathrm{c} \pm}=-\frac{1}{2}\left( \pm \omega_{\mathrm{H}}+\sqrt{\omega_{\mathrm{H}}^{2}+4 \omega_{\mathrm{p}}^{2}}\right)
\end{aligned}
$$

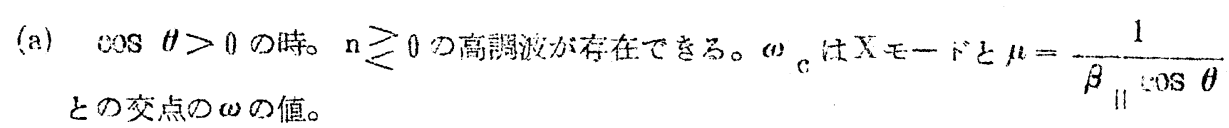

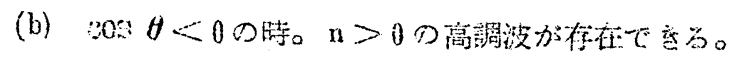

A-1図 加这電子比上って作られる放纣場の計算の為の座福。

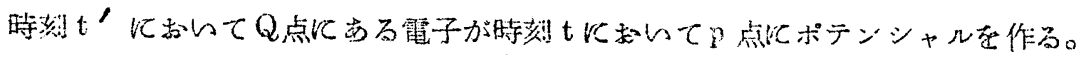

$$
\mathrm{R}=\overrightarrow{\mathrm{QP}} \quad \mathrm{r}=\overrightarrow{\mathrm{OP}} \quad \mathrm{n}=\frac{\mathrm{r}}{|\mathrm{r}|}
$$




\section{小川・短井}

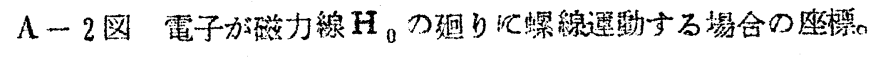

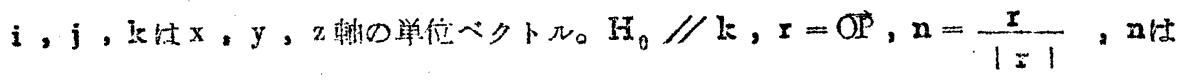
$\mathbf{j}$ 一的平面上飞方上す而。

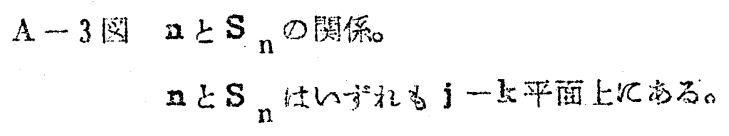

